\title{
mHealth Apps as Effective Persuasive Health Technology: Contextualizing the "Necessary" Functionalities
}

Allen McLean, MN, MSc, RN

University of Saskatchewan, Saskatoon, SK, Canada

Corresponding Author:

Allen McLean, MN, MSc, RN

University of Saskatchewan

5D40 Health Sciences Building

107 Wiggins Road

Saskatoon, SK,

Canada

Phone: 16048090919

Email: allen.mclean@usask.ca

\begin{abstract}
Persuasive health technology (PHT) is any technology purposely designed to influence, reinforce, change, or shape health-related attitudes or behaviors. Behavioral interventions can be developed for the purpose of maintaining or improving a person's health status. Delivering behavioral interventions via PHTs is a promising approach for encouraging healthy behaviors among individuals and populations. Important attributes of all PHTs include their functionalities. A functionality refers to any useful features, functions, capabilities, or technologies associated with computer hardware or software. Creating effective PHTs requires a deliberate selection of appropriate functionalities for supporting specific behavioral interventions. The number and types of functionalities necessary to create an effective PHT will be specific to the context of each project, influenced by project objectives, stakeholder goals, behavioral interventions, and a variety of real-world constraints. Selecting appropriate functionalities can be challenging. Fortunately, there are frameworks and models developed specifically for guiding the design of PHTs. The Persuasive Systems Design model describes 4 categories, and 28 design principles for creating effective persuasive interventions. These same design principles could also be useful for guiding the selection of appropriate functionalities.
\end{abstract}

(JMIR Nursing 2020;3(1):e19302) doi: 10.2196/19302

\section{KEYWORDS}

persuasive health technology; behavioral intervention; persuasive systems design; eHealth; mHealth; nursing informatics

\section{Introduction}

\section{Health Determinants}

Numerous entwined factors influence a person's individual health status, collectively known as the determinants of health. Some of these determinants are modifiable, while others are not. Organizations such as Health Canada [1] and the World Health Organization [2] include a person's individual behaviors as a determinant of that person's current health state, and future health trajectory. These behaviors include important decisions commonly made about, among others, diet, exercise, sexual activity, substance use, medication adherence, and vaccination [3].

Importantly, many individual health behaviors are modifiable, meaning that well-crafted behavioral interventions can be developed for the purpose of maintaining or improving a person's individual health status. Behavioral health interventions are expected to remain important strategies for promoting health and well-being, preventing illness, and managing disease well into the foreseeable future [4,5]. Alongside traditional approaches (eg, individual coaching, motivational interviewing), delivering behavioral interventions via persuasive health technologies (ie, PHTs, such as mobile health [mHealth] technology) is a promising newer approach for encouraging healthy behaviors among individuals and populations [5-7]. However, these objectives can only be achieved if the designers and developers of these interventions and technologies select functionalities that provide effective support for achieving their goals.

\section{Objectives}

This paper will describe the constellation of functionalities (eg, features, technologies) required for developing an effective mHealth-based PHT. Useful frameworks for designing PHTs will be introduced. A detailed list of current mobile IT 
functionalities will be presented, along with an example demonstrating how nurse researchers might design an effective PHT by matching various mHealth functionalities with a selected design framework and a behavioral intervention encouraging social/physical distancing. Finally, examples suggesting how 2 currently available mHealth systems might be adapted to serve as effective PHTs will be discussed.

\section{Background}

Persuasive technology is any technology (eg, computers, websites, smartphones and apps, tablets, wearables, computer games) purposely designed to change attitudes or behaviors [8]. PHT (eg, electronic health [eHealth] programs, mHealth apps) is a specialized co-discipline that focuses on influencing, reinforcing, changing, or shaping health-related attitudes or behaviors [9] without using coercion or deception [10], and is most often used for health promotion and prevention or disease management [11]. PHTs for disease management help people comply with and adhere to treatment directives, such as better medication adherence or diabetes management [12]. The study of PHTs includes the design, research, ethics, and analysis of these interactive computing products [13]. The use of PHTs is growing rapidly in many areas of health and wellness [9]. Examples include PHTs encouraging behavior change in physical activity, healthy eating, tobacco cessation, risky sexual behavior, pregnancy, and dental health [12]. Peer-reviewed research has demonstrated benefits from the use of PHTs for promotion, prevention, and management across some chronic diseases [14-17], but there is tremendous opportunity for further study [12].

The WHO Global Observatory for eHealth [18] defines mHealth as medical and public health practice supported by mobile devices, such as smartphones, patient monitoring devices, personal digital assistants, and other wireless devices. Experts in the field of behavioral science agree that influencing healthy behavior change is notoriously difficult $[3,19]$. While there is increasing interest from researchers and clinicians in harnessing mHealth as a means of delivering behavioral interventions, academic research on the development and evaluation of effective health-related mHealth behavioral interventions is still in the early stages of study. Nevertheless, recent peer-reviewed studies and systematic reviews support (to varying degrees) the use of behavioral interventions delivered by mHealth across many populations and problems. Examples include sexual health [20], cardiovascular disease [21], diabetes [22-30], adolescents and young adults [31], ecological momentary assessments [32], health technology assessment [33], chronic disease management [34-36], sedentary behavior [37], diet and physical activity [38], and diabetic foot ulcers [39-41].

As a research tool, some mHealth solutions offer real-time and real-world measurements of phenomena. Some researchers ask study participants to maintain paper-and-pencil logs. However, the labor-intensive and intrusive nature of paper-and-pencil recording has limited its clinical applicability and underscores the concern that data can be backfilled by patients [42]. Smartphones offer a potential solution by enabling research through apps designed to prompt, collect, time stamp, and securely transfer patient data. Furthermore, researchers believe that conducting studies on smartphones is important because data collection is private, and may reduce potential bias from the Hawthorne effect.

Creating these technologies can be a demanding, but wonderfully creative and beneficial endeavor-developing solutions that combine knowledge from the health sciences, behavioral psychology, and software engineering for tackling many of the health problems experienced today. Each mHealth-based PHT will be made-to-measure, and the design and development of each behavioral intervention and technology will depend on a variety of factors, including project goals, health problem(s), mix of stakeholders (and their individual, possibly conflicting aspirations), advice received from consultation with subject-matter experts, input and feedback from users, available technologies, financial constraints, ethical considerations, and available functionalities $[43,44]$.

For the purposes of this paper, a functionality refers to any useful technologies, capabilities, features, or functions associated with computer software or hardware, in particular mobile electronic devices (eg, smartphones, tablets, wearable devices) [45]. It is important to understand that functionalities are chosen to support a behavioral intervention [46], and intervention development and functionality selection should proceed in an iterative manner, each informing the other [6]. Furthermore, it is important to understand that the number and types of functionalities necessary to create an effective PHT will be specific to each mHealth project, that is, context will determine which functionalities are necessary, not algorithms or formulae [43]. For example, Dobson et al [47] conducted a randomized controlled trial investigating the effectiveness of a smartphone-based behavioral health intervention for supporting self-management among adults living with poorly controlled diabetes. The intervention group received a tailored package of SMS (short message service) text messages, in addition to usual care. The SMS text messages provided information, support, motivation, and reminders related to diabetes self-management and lifestyle behaviors. These researchers relied on a single mHealth functionality and technology (ie, SMS text messaging) and smartphones to deliver their intervention and answer their research and clinical questions. Notably, even when using these few functionalities, the intervention group demonstrated a significant reduction in $\mathrm{HbA}^{\mathrm{lc}}$ (hemoglobin $\mathrm{A}^{\text {lc }}$; blood glucose), and a significant improvement in foot care behaviors, at 9 months' follow-up.

A more complex PHT was proposed by Hussain et al [48], a personalized behavioral intervention for promoting awareness of optimal sun intake (ensuring sufficient vitamin D production), balanced with promoting safe sun exposure. Their persuasive health solution uses both smartphone and wearable technologies, together with multiple functionalities for achieving their project and clinical goals. Their mHealth app collects current weather, global positioning system (GPS), light exposure, and UV data from user's smartphones and sensors in the wearable device. This information is then fed into a custom-built smartphone app providing personalized information to each user by tracking cumulative sun exposure and triggering appropriate smartphone 
alerts and UVI (UV index) warnings via SMS text messaging [49].

Creating effective PHTs requires a deliberate selection of appropriate functionalities for supporting specific behavioral interventions. In many ways, the process for developing an effective mHealth-based persuasive technology is similar to the development process followed for any other well-organized, well-executed software or technology development project $[6,43,44]$, and correctly selecting which functionalities are needed is an important step in the development process [50]. However, even when following a recommended (eg, Agile, Scrum) software engineering methodology [6,51], this process is challenging, and choosing the appropriate functionalities that will result in an effective mHealth-based technology is not always so straightforward. Each PHT will be fit-for-purpose, meaning that cookbook solutions-such as if population $\mathrm{X}$ is experiencing health problem $\mathrm{Y}$, then use functionalities $\mathrm{a}, \mathrm{b}$, and $\mathrm{c}$ to support behavioral intervention $\mathrm{Z}-\mathrm{do}$ not exist. Confusing matters further, a functionality deemed useful in one context may not be in another. Fortunately, designers and developers can look to a small number of conceptual frameworks and models developed specifically for guiding the design of PHTs [52].

\section{Frameworks}

Once a behavioral health intervention has been developed, and the decision made to deliver the intervention using mHealth technology, the intervention must be operationalized via the selected mobile IT functionalities (eg, SMS, GPS, sensors, cameras). A number of frameworks and models have proven useful for developing PHTs [10,52-54]. Among these, the Persuasive Systems Design (PSD) model is well-respected, and considered a state-of-the-art framework for designing and evaluating persuasive systems [9]. Many systematic reviews report limited evidence for the efficacy of mHealth apps [55], but note that projects developed using a conceptual framework or behavior theory are often more effective [5,51].

The PSD model is grounded in multiple theoretical constructs and established persuasive design techniques, with a focus on supporting the transfer of design specifications into software functionalities [56]. The PSD model has been applied widely across many disciplines, with researchers actively evaluating its use in many domains [17,57-62]. The PSD framework describes 28 persuasive design principles (Textbox 1) in 4 categories: primary task support, computer-human dialogue support, system credibility support, and social support $[9,10]$. The design principles found in the primary task support category support people when carrying out a primary task (eg, supporting regular blood glucose monitoring for people living with diabetes). Any interactive system provides some degree of system feedback to its users, and there are multiple design principles related to dialogue support that help users keep moving toward their goal or target behavior. The principles located in the system credibility category not surprisingly describe various ways to design a persuasive system with greater credibility. Lastly, the design principles found in the social support category describe how to motivate users by leveraging social influence using concepts such as competition or cooperation $[9,10,56]$. 
Textbox 1. Persuasive Systems Design framework: design principles [10].

\section{Primary task support}

i. Reduction: A system that reduces complex behavior into simple tasks helps users perform the target behavior, and it may increase the benefit-to-cost ratio of a behavior.

ii. Tunneling: Using the system to guide users through a process or experience provides opportunities to persuade along the way.

iii. Tailoring: Information provided by a system is more persuasive if it is tailored to the needs, interests, personality, usage context, or other factors relevant to a user group.

iv. Personalization: A system that offers personalized content or services has a greater capability for persuasion.

v. Self-monitoring: A system that keeps track of one's own performance or status supports the user in achieving goals.

vi. Simulation: A system that provide simulations can persuade by enabling users to observe immediately the link between cause and effect.

vii. Rehearsal: A system providing a means by which to rehearse a behavior that can enable people to change their attitudes or behavior in the real world.

\section{Computer-human dialogue support}

i. Praise: By offering praise, a system can make users more open to persuasion.

ii. Rewards: Systems that reward target behaviors may have greater persuasive powers.

iii. Reminders: If a system reminds users of their target behavior, the users will more likely achieve their goals.

iv. Suggestion: Systems offering fitting suggestions will have greater persuasive powers.

v. Similarity: People are more readily persuaded through systems that remind them of themselves in some meaningful way.

vi. Liking: A system that is visually attractive for its users is likely to be more persuasive.

vii. Social role: If a system adopts a social role, users are more likely to use it for persuasive purposes.

\section{System credibility support}

i. Trustworthiness: A system viewed as trustworthy will have increased powers of persuasion.

ii. Expertise: Incorporating expertise will have increased powers of persuasion.

iii. Surface credibility: System credibility is based on a firsthand inspection.

iv. Real-world feel: A system that highlights people or organization behind its content or services will have more credibility.

v. Authority: A system leveraging roles of authority will be more persuasive.

vi. Third-party endorsements: Third-party endorsements, especially from well-known and respected sources, boost perceptions of system credibility.

vii. Verifiability: Credibility perceptions will be enhanced if a system makes it easy to verify the accuracy of site content via outside sources.

\section{Social support}

i. Social learning: A person will be more motivated to perform a target behavior if he or she can use a system to observe others performing the behavior.

ii. Social comparison: System users will have a greater motivation to perform the target behavior if they can compare their performance with the performance of others.

iii. Normative influence: A system can leverage normative influence or peer pressure to increase the likelihood that a person will adopt a target behavior.

iv. Social facilitation: System users are more likely to perform target behavior if they discern via the system that others are performing the behavior along with them.

v. Cooperation: A system can motivate users to adopt a target attitude or behavior by leveraging humans' natural drive to co-operate.

vi. Competition: A system can motivate users to adopt a target attitude or behavior by leveraging humans' natural drive to compete.

vii. Recognition: By offering public recognition for an individual or group, a system can increase the likelihood that a person/group will adopt a target behavior.

\section{Functionalities}

Modern mobile devices provide many functionalities; even low-cost phones, tablets, and wearables (eg, smart watches, fitness trackers) can be useful as PHTs. Functionalities will vary

by device, often influenced by cost, manufacturer, or hardware specifications, though many will share a number of common features and capabilities. Important hardware functionalities include the display (usually touchscreen), keyboard, headphone jack, camera, volume controls, water-resistant capability, and 
rechargeable battery. Important communication functionalities include calling, SMS text messaging, multimedia messaging service (MMS; audio and video playback), web browser, email, and apps $[63,64]$. An incredible amount of sensor data can be collected, including location data (GPS, latitude/longitude, altitude, speed, and bearing), motion data (accelerometer, gravity, gyroscope, magnetic field, and pedometer), environmental data (ambient temperature, light, pressure, proximity, and relative humidity), network data (Bluetooth and Bluetooth networks), and others including battery usage, screen state, app usage, and ambient audio [65]. Wearable devices can also collect a variety of physiological data such as heart rate, sleep tracking, electrocardiogram, steps, and calories burned, to name a few $[66,67]$.

It is meaningless to think of each functionality, or combination of functionalities, as effective or ineffective in the context of designing or developing a PHT. An effective mHealth-based solution is the result of selecting appropriate functionalities supporting a specific behavioral intervention. Linking functionalities to the PSD model can assist with this process.

\section{Example}

Imagine a team of nurse researchers planning the design for an effective PHT delivered via mHealth technology. To achieve this goal, these nurses must create a behavioral intervention, then select a design framework, and choose functionalities that can operationalize their intervention. The PSD framework describes 28 persuasive design principles (Textbox 1) in 4 categories; these same design principles are useful for guiding the selection of appropriate functionalities. Textbox 2 illustrates how an imagined behavioral intervention (encouraging social/physical distancing) suggested during a global pandemic (eg, COVID-19) could be developed by linking design principles from the PSD model with various context-appropriate mHealth functionalities. It is important to note that not every design principle will be useful for selecting functionalities that support a behavioral intervention; this will be project specific, and limited by a variety of real-world constraints such as budgets or technologies. 
Textbox 2. Examples linking design principles with functionalities for the purpose of developing a PHT for encouraging social/physical distancing.

\section{Primary task support}

i. Reduction: A system that reduces complex behavior into simple tasks helps users perform the target behavior, and it may increase the benefit-to-cost ratio of a behavior.

For example, using SMS text or MMS messages, or the ability to link to instructional web-based videos for delivering social/physical distancing instructions

ii. Tailoring: Information provided by a system is more persuasive if it is tailored to the needs, interests, personality, usage context, or other factors relevant to a user group.

For example, using feedback from individual user surveys, alerts, Bluetooth data, or sensor data that provides personalized social/physical distancing information important for each individual user and delivered via SMS text or MMS messaging

iii. Self-monitoring: A system that keeps track of one's own performance or status supports the user in achieving goals.

For example, feedback and information provided to users about their daily social/physical distancing habits directly from individual sensor data, Bluetooth data, or health and wellness tracking apps

\section{Computer-human dialogue support}

i. Praise: By offering praise, a system can make users more open to persuasion.

For example, praise delivered by automated SMS text or MMS messages, triggered by survey responses, or physiologic and proximity sensor data when proper social/physical distancing practices are recorded

ii. Reminders: If a system reminds users of their target behavior, the users will more likely achieve their goals.

For example, alerts and reminder messages about effective social/physical distancing delivered via mobile devices or wearables and triggered by, for example, time of day, GPS location, motion sensors, or proximity sensors

iii. Suggestion: Systems offering fitting suggestions will have greater persuasive powers.

For example, suggestions for improving the effectiveness of social/physical distancing practices delivered via SMS text or MMS messages and triggered by, for instance, time of day, GPS location, Bluetooth data, motion or proximity sensors

\section{System credibility support}

i. Surface credibility: System credibility is based on a firsthand inspection.

For example, building systems using professional user experience software design

ii. Authority: A system leveraging roles of authority will be more persuasive.

For example, including content from local, national, or international health agencies and their social/physical distancing recommendations

iii. Third-party endorsements: Third-party endorsements, especially from well-known and respected sources, boost perceptions of system credibility. For example, including SMS text messages from family members, friends, or celebrities

\section{Social support}

i. Social facilitation: System users are more likely to perform target behavior if they discern via the system that others are performing the behavior along with them.

For example, sharing user data from health or wellness tracking apps, individual sensor data, or survey responses via SMS text or MMS messaging may also facilitate cooperation

ii. Competition: A system can motivate users to adopt a target attitude or behavior by leveraging humans' natural drive to compete.

For example, sharing user data from health or wellness tracking apps, individual sensor data, or survey responses via SMS text or MMS messaging, or using a bespoke app that tracks social/physical distancing data

iii. Recognition: By offering public recognition for an individual or group, a system can increase the likelihood that a person/group will adopt a target behavior.

For example, sharing user or group progress with other users about social/physical distancing

\section{Conclusions}

Creating effective mHealth-based PHTs requires a deliberate selection of necessary functionalities. These functionalities are only necessary in the context of providing support for specific behavioral interventions. To operationalize a behavioral intervention, nurse researchers can build a bespoke PHT themselves (assuming they have the required technical skills), hire professional designers and developers (assuming they have significant financial resources), or modify an existing platform (assuming such platforms exist, and permission to modify is possible at an affordable cost). 
This third option is appealing because it can be quick to develop, affordable, and requires limited technical skills. For example, the Ethica research platform provides researchers with many functionalities [68] and could be adapted for use as a persuasive technology. When comparing Ethica functionalities with the PSD model design principles, it appears Ethica could offer support for every principle, meaning that Ethica could offer support for any behavioral intervention developed using the PSD model. By contrast, the REDCap research platform provides researchers with far fewer functionalities [69], mainly lacking the ability to process sensor data, but it could also be adapted for use as a persuasive technology. This means REDCap could offer support for a smaller number of PSD model design principles and behavioral interventions. Does this mean REDCap is less useful than Ethica as a PHT? Not necessarily; as argued in this paper, context and requirements will determine the necessary functionalities.

\section{Acknowledgments}

I thank Dr Nate Osgood and Dr Donna Goodridge for expert advice, support, and enthusiastic encouragement.

\section{Conflicts of Interest}

None declared.

\section{References}

1. Health Canada. Social Determinants of Health and Health Inequalities. Ottawa: Health Canada; 2019 Jul 25. URL: https:/ /www.canada.ca/en/public-health/services/health-promotion/population-health/what-determines-health.html [accessed 2020-07-01]

2. World Health Organization. Social determinants of health. Geneva, Switzerland: World Health Organization; 2020. URL: https://www.who.int/social determinants/en/ [accessed 2020-07-01]

3. Conner M, Norman P. Health behaviour: Current issues and challenges. Psychol Health 2017 Aug 14;32(8):895-906. [doi: 10.1080/08870446.2017.1336240] [Medline: 28612656]

4. Walsh J, Morrissey E. Psychological principles and health behaviour change: applications to eHealth. In: van Gemert-Pijnen L, Kelders S, Kip H, Sanderman R, editors. eHealth Research, Theory and Development: A Multidisciplinary Approach. New York: Routledge; 2018:27-47.

5. Orji R, Moffatt K. Persuasive technology for health and wellness: State-of-the-art and emerging trends. Health Informatics J 2018 Mar 31;24(1):66-91. [doi: 10.1177/1460458216650979] [Medline: 27245673]

6. Kelders S, Howard M. Opportunities of technology to promote health and well-being. In: van Gemert-Pijnen L, Kelders S, Kip H, Sanderman R, editors. eHealth Research, Theory and Development: A Multidisciplinary Approach. New York: Routledge; 2018:48-68.

7. van Gemert-Pijnen L. The future of eHealth, technology and psychology. In: van Gemert-Pijnen L, Kelders S, Kip H, Sanderman R, editors. eHealth Research, Theory and Development: A Multidisciplinary Approach. New York: Routledge; 2018:319-329.

8. Persuasive Technology. 2015 Mar 23. URL: https://www.technologyreview.com/s/535826/technology-and-persuasion/ ?set=535816 [accessed 2020-07-01]

9. van Gemert-Pijnen L, Kelders S, Beerlage-de Jong N, Oinas-Kukkonen H. Persuasive health technology. In: van Gemert-Pijnen L, Kelders S, Kip H, Sanderman R, editors. eHealth Research, Theory and Development: A Multidisciplinary Approach. New York: Routledge; 2018:228-246.

10. Oinas-Kukkonen H, Harjumaa M. Persuasive Systems Design: Key Issues, Process Model, and System Features. CAIS 2009;24:485-500. [doi: 10.17705/1 cais.02428]

11. University of Twente. eHealth: Combining psychology, technology and health. 2018. URL: https://www.futurelearn.com/ courses/ehealth [accessed 2020-01-08]

12. Orji R, Moffatt K. Persuasive technology for health and wellness: State-of-the-art and emerging trends. Health Informatics Journal 2018 Mar 01;24(1):66-91 [FREE Full text] [doi: 10.1177/1460458216650979]

13. Stanford Persuasive Technology Lab. Captology. 2019. URL: https://captology.stanford.edu/ [accessed 2020-01-08]

14. Berg M, Linden K, Adolfsson A, Sparud Lundin C, Ranerup A. Web-Based Intervention for Women With Type 1 Diabetes in Pregnancy and Early Motherhood: Critical Analysis of Adherence to Technological Elements and Study Design. J Med Internet Res 2018 May 02;20(5):e160 [FREE Full text] [doi: 10.2196/jmir.9665] [Medline: 29720365]

15. Kim JY, Wineinger NE, Steinhubl SR. The Influence of Wireless Self-Monitoring Program on the Relationship Between Patient Activation and Health Behaviors, Medication Adherence, and Blood Pressure Levels in Hypertensive Patients: A Substudy of a Randomized Controlled Trial. J Med Internet Res 2016 Jun 22;18(6):e116 [FREE Full text] [doi: 10.2196/jmir.5429] [Medline: 27334418]

16. Portz J, Miller A, Foster B, Laudeman L. Persuasive features in health information technology interventions for older adults with chronic diseases: a systematic review. Health Technol 2016 Mar 23;6(2):89-99 [FREE Full text] [doi: $10.1007 / \mathrm{s} 12553-016-0130-\mathrm{x}]$ 
17. Wang Y, Wu L, Lange JP, Fadhil A, Reiterer H. Persuasive technology in reducing prolonged sedentary behavior at work: a systematic review. Smart Health 2018 May 22;7-8:19-30. [doi: 10.1016/j.smhl.2018.05.002]

18. World Health Organization Global Observatory for eHealth. mHealth: New horizons for health through mobile technologies. 2011. URL: http://www.who.int/goe/publications/goe_mhealth_web.pdf [accessed 2020-01-15]

19. Kelly M, Barker M. Why is changing health-related behaviour so difficult? Public Health 2016 Jul;136:109-116 [FREE Full text] [doi: 10.1016/j.puhe.2016.03.030] [Medline: 27184821]

20. Burns K, Keating P, Free C. A systematic review of randomised control trials of sexual health interventions delivered by mobile technologies. BMC Public Health 2016 Aug 12;16(1):778 [FREE Full text] [doi: 10.1186/s12889-016-3408-z] [Medline: 27514851]

21. Pfaeffli Dale L, Dobson R, Whittaker R, Maddison R. The effectiveness of mobile-health behaviour change interventions for cardiovascular disease self-management: A systematic review. Eur J Prev Cardiol 2016 May;23(8):801-817 [FREE Full text] [doi: 10.1177/2047487315613462] [Medline: 26490093]

22. Aikens J, Zivin K, Trivedi R, Piette J. Diabetes self-management support using mHealth and enhanced informal caregiving. J Diabetes Complications 2014;28(2):171-176 [FREE Full text] [doi: 10.1016/j.jdiacomp.2013.11.008] [Medline: 24374137]

23. Bonoto BC, de Araújo VE, Godói IP, de Lemos LLP, Godman B, Bennie M, et al. Efficacy of Mobile Apps to Support the Care of Patients With Diabetes Mellitus: A Systematic Review and Meta-Analysis of Randomized Controlled Trials. JMIR Mhealth Uhealth 2017 Mar 01;5(3):e4 [FREE Full text] [doi: 10.2196/mhealth.6309] [Medline: 28249834]

24. Desveaux L, Shaw J, Saragosa M, Soobiah C, Marani H, Hensel J, et al. A Mobile App to Improve Self-Management of Individuals With Type 2 Diabetes: Qualitative Realist Evaluation. J Med Internet Res 2018 Mar 16;20(3):e81 [FREE Full text] [doi: 10.2196/jmir.8712] [Medline: 29549070]

25. Hood M, Wilson R, Corsica J, Bradley L, Chirinos D, Vivo A. What do we know about mobile applications for diabetes self-management? A review of reviews. J Behav Med 2016 Dec;39(6):981-994 [FREE Full text] [doi: 10.1007/s10865-016-9765-3] [Medline: 27412774]

26. Hou C, Carter B, Hewitt J, Francisa T, Mayor S. Do Mobile Phone Applications Improve Glycemic Control (HbA1c) in the Self-management of Diabetes? A Systematic Review, Meta-analysis, and GRADE of 14 Randomized Trials. Diabetes Care 2016 Nov;39(11):2089-2095 [FREE Full text] [doi: 10.2337/dc16-0346] [Medline: 27926892]

27. Hunt CW. Technology and diabetes self-management: An integrative review. World J Diabetes 2015 Mar 15;6(2):225-233 [FREE Full text] [doi: 10.4239/wjd.v6.i2.225] [Medline: 25789104]

28. Kitsiou S, Paré G, Jaana M, Gerber B. Effectiveness of mHealth interventions for patients with diabetes: An overview of systematic reviews. PLoS One 2017;12(3):e0173160 [FREE Full text] [doi: 10.1371/journal.pone.0173160] [Medline: 28249025]

29. Nelson LA, Wallston KA, Kripalani S, Greevy RA, Elasy TA, Bergner EM, et al. Mobile Phone Support for Diabetes Self-Care Among Diverse Adults: Protocol for a Three-Arm Randomized Controlled Trial. JMIR Res Protoc 2018 Apr 10;7(4):e92 [FREE Full text] [doi: 10.2196/resprot.9443] [Medline: 29636319]

30. Wu Y, Yao X, Vespasiani G, Nicolucci A, Dong Y, Kwong J, et al. Mobile App-Based Interventions to Support Diabetes Self-Management: A Systematic Review of Randomized Controlled Trials to Identify Functions Associated with Glycemic Efficacy. JMIR Mhealth Uhealth 2017 Mar 14;5(3):e35 [FREE Full text] [doi: 10.2196/mhealth.6522] [Medline: 28292740]

31. Dennison L, Morrison L, Conway G, Yardley L. Opportunities and challenges for smartphone applications in supporting health behavior change: qualitative study. J Med Internet Res 2013 Apr;15(4):e86 [FREE Full text] [doi: 10.2196/jmir.2583] [Medline: 23598614]

32. Heron K, Smyth J. Ecological momentary interventions: Incorporating mobile technology into psychosocial and health behaviour treatments. British Journal of Health Psychology 2010;15(1):1-39 [FREE Full text] [doi: 10.1348/135910709x466063]

33. McKay F, Cheng C, Wright A, Shill J, Stephens H, Uccellini M. Evaluating mobile phone applications for health behaviour change: A systematic review. J Telemed Telecare 2016 Oct 18;24(1):22-30 [FREE Full text] [doi:

$10.1177 / 1357633 \times 16673538]$

34. Anderson K, Burford O, Emmerton L. Mobile Health Apps to Facilitate Self-Care: A Qualitative Study of User Experiences. PLoS One 2016;11(5):e0156164 [FREE Full text] [doi: 10.1371/journal.pone.0156164] [Medline: 27214203]

35. Free C, Phillips G, Galli L, Watson L, Felix L, Edwards P, et al. The effectiveness of mobile-health technology-based health behaviour change or disease management interventions for health care consumers: a systematic review. PLoS Med 2013;10(1):e1001362 [FREE Full text] [doi: 10.1371/journal.pmed.1001362] [Medline: 23349621]

36. Whitehead L, Seaton P. The Effectiveness of Self-Management Mobile Phone and Tablet Apps in Long-term Condition Management: A Systematic Review. J Med Internet Res 2016 May;18(5):e97 [FREE Full text] [doi: 10.2196/jmir.4883] [Medline: 27185295]

37. Stephenson A, McDonough SM, Murphy MH, Nugent CD, Mair JL. Using computer, mobile and wearable technology enhanced interventions to reduce sedentary behaviour: a systematic review and meta-analysis. Int J Behav Nutr Phys Act 2017 Aug 11;14(1):105 [FREE Full text] [doi: 10.1186/s12966-017-0561-4] [Medline: 28800736] 
38. Schoeppe S, Alley S, Van Lippevelde W, Bray NA, Williams SL, Duncan MJ, et al. Efficacy of interventions that use apps to improve diet, physical activity and sedentary behaviour: a systematic review. Int J Behav Nutr Phys Act 2016 Dec 07;13(1):127 [FREE Full text] [doi: 10.1186/s12966-016-0454-y] [Medline: 27927218]

39. Bauer V, Goodman N, Lapin B, Cooley C, Wang E, Craig TL, et al. Text Messaging to Improve Disease Management in Patients With Painful Diabetic Peripheral Neuropathy. Diabetes Educ 2018 Jun;44(3):237-248 [FREE Full text] [doi: 10.1177/0145721718767400] [Medline: 29589820]

40. Boodoo C, Perry JA, Hunter PJ, Duta DI, Newhook SCP, Leung G, et al. Views of Patients on Using mHealth to Monitor and Prevent Diabetic Foot Ulcers: Qualitative Study. JMIR Diabetes 2017 Sep 15;2(2):e22 [FREE Full text] [doi: 10.2196/diabetes.8505] [Medline: 30291089]

41. Ploderer B, Brown R, Seng LSD, Lazzarini PA, van Netten JJ. Promoting Self-Care of Diabetic Foot Ulcers Through a Mobile Phone App: User-Centered Design and Evaluation. JMIR Diabetes 2018 Oct 10;3(4):e10105 [FREE Full text] [doi: 10.2196/10105] [Medline: $\underline{30305266]}$

42. Torous J, Staples P, Shanahan M, Lin C, Peck P, Keshavan M, et al. Utilizing a Personal Smartphone Custom App to Assess the Patient Health Questionnaire-9 (PHQ-9) Depressive Symptoms in Patients With Major Depressive Disorder. JMIR Ment Health 2015 Mar;2(1):e8 [FREE Full text] [doi: 10.2196/mental.3889] [Medline: 26543914]

43. Kip H, Beerlage-de Jong N, Wentzel J. The contextual inquiry. In: van Gemert-Pijnen L, Kelders S, Kip H, Sanderman R, editors. eHealth Research, Theory and Development: A Multidisciplinary Approach. New York: Routledge; 2018:167-186.

44. Nieuwenhuis B. Value proposition design and business modelling. In: van Gemert-Pijnen L, Kelders S, Kip H, Sanderman R, editors. eHealth Research, Theory and Development: A Multidisciplinary Approach. New York: Routledge; 2018:187-206.

45. Merriam-Webster. Functionality. 2020. URL: https://www.merriam-webster.com/dictionary/functionality [accessed 2020-01-20]

46. Patel MS, Asch DA, Volpp KG. Wearable devices as facilitators, not drivers, of health behavior change. JAMA 2015 Feb 03;313(5):459-460. [doi: 10.1001/jama.2014.14781] [Medline: 25569175]

47. Dobson R, Whittaker R, Jiang Y, Maddison R, Shepherd M, McNamara C, et al. Effectiveness of text message based, diabetes self management support programme (SMS4BG): two arm, parallel randomised controlled trial. BMJ 2018 May 17;361:k1959 [FREE Full text] [doi: 10.1136/bmj.k1959] [Medline: 29773539]

48. Hussain MS, Cripwell L, Berkovsky S, Freyne J. Promoting UV exposure awareness with persuasive, wearable technologies. In: Georgiou A, Schaper LK, Whetton S, editors. Digital Health Innovation for Consumers, Clinicians, Connectivity and Community. Amsterdam: IOS Press; 2016:48-54.

49. Health Informatics Society of Australia. Promoting UV Exposure Awareness With Persuasive, Wearable Technologies.: Health Informatics Society of Australia; 2016. URL: https://www.hisa.org.au/wp-content/uploads/hic2016/wednesday/ Sazzard-Hussain.pdf [accessed 2020-01-20]

50. Burns C. Human-centred design. In: van Gemert-Pijnen L, Kelders S, Kip H, Sanderman R, editors. eHealth Research, Theory and Development: A Multidisciplinary Approach. New York: Routledge; 2018:207-227.

51. Hekler EB, Klasnja P, Riley WT, Buman MP, Huberty J, Rivera DE, et al. Agile science: creating useful products for behavior change in the real world. Behav Med Pract Policy Res 2016 Feb 26;6(2):317-328. [doi: 10.1007/s13142-016-0395-7]

52. Mohr DC, Schueller SM, Montague E, Burns MN, Rashidi P. The behavioral intervention technology model: an integrated conceptual and technological framework for eHealth and mHealth interventions. J Med Internet Res 2014 Jun 05;16(6):e146 [FREE Full text] [doi: 10.2196/jmir.3077] [Medline: 24905070]

53. Ritterband LM, Thorndike FP, Cox DJ, Kovatchev BP, Gonder-Frederick LA. A behavior change model for internet interventions. Ann Behav Med 2009 Aug 4;38(1):18-27 [FREE Full text] [doi: 10.1007/s12160-009-9133-4] [Medline: 19802647]

54. Fogg B. Tiny Habits: The Small Changes That Change Everything. Stanford: Houghton Mifflin Harcourt; 2019.

55. Marcolino MS, Oliveira JAQ, D'Agostino M, Ribeiro AL, Alkmim MBM, Novillo-Ortiz D. The Impact of mHealth Interventions: Systematic Review of Systematic Reviews. JMIR Mhealth Uhealth 2018 Jan 17;6(1):e23 [FREE Full text] [doi: 10.2196/mhealth.8873] [Medline: 29343463]

56. Lehto T, Oinas-Kukkonen H. Examining the Persuasive Potential of Web-based Health Behavior Change Support Systems. THCI 2015 Sep 30;7(3):126-140. [doi: 10.17705/1thci.00069]

57. Asbjørnsen RA, Smedsrød ML, Solberg Nes L, Wentzel J, Varsi C, Hjelmesæth J, et al. Persuasive System Design Principles and Behavior Change Techniques to Stimulate Motivation and Adherence in Electronic Health Interventions to Support Weight Loss Maintenance: Scoping Review. J Med Internet Res 2019 Jun 21;21(6):e14265 [FREE Full text] [doi: 10.2196/14265] [Medline: 31228174]

58. Matthews J, Win KT, Oinas-Kukkonen H, Freeman M. Persuasive Technology in Mobile Applications Promoting Physical Activity: a Systematic Review. J Med Syst 2016 Jan 9;40(3):72. [doi: 10.1007/s10916-015-0425-x]

59. Orji R, Oyibo K, Lomotey RK, Orji FA. Socially-driven persuasive health intervention design: Competition, social comparison, and cooperation. Health Informatics J 2019 Dec 25;25(4):1451-1484. [doi: 10.1177/1460458218766570] [Medline: 29801426] 
60. Geuens J, Swinnen TW, Westhovens R, de Vlam K, Geurts L, Vanden Abeele V. A Review of Persuasive Principles in Mobile Apps for Chronic Arthritis Patients: Opportunities for Improvement. JMIR Mhealth Uhealth 2016 Oct 13;4(4):e118 [FREE Full text] [doi: 10.2196/mhealth.6286] [Medline: 27742604]

61. Wais-Zechmann B, Gattol V, Neureiter K, Orji R, Tscheligi M. Persuasive technology to support chronic health conditions: investigating the optimal persuasive strategies for persons with COPD. In: Ham J, Karapanos E, Morita P, Burns C, editors. Persuasive2018: International Conference on Persuasive Technology. Lecture Notes in Computer Science. Cham: Springer; 2018:255-266.

62. Radomski A, Wozney L, McGrath P, Huguet A, Hartling L, Dyson M, et al. Design and Delivery Features That May Improve the Use of Internet-Based Cognitive Behavioral Therapy for Children and Adolescents With Anxiety: A Realist Literature Synthesis With a Persuasive Systems Design Perspective. J Med Internet Res 2019 Feb 05;21(2):e11128 [FREE Full text] [doi: 10.2196/11128] [Medline: $\underline{\text { 30720436] }}$

63. Apple Inc. 2020. iPhone URL: https://www.apple.com/ca/iphone/ [accessed 2020-02-02]

64. Apple Inc. 2020. iPad URL: https://www.apple.com/ca/ipad/ [accessed 2020-02-01]

65. Ethica Data Inc . 2020. Ethica. Data Sources URL: https://learn.ethicadata.com/documentation/data-sources/data-sources/ [accessed 2020-02-02]

66. Apple Inc. 2020. Watch URL: https://www.apple.com/ca/watch/ [accessed 2020-02-02]

67. Fitbit Inc. 2020. Fitbit Technology URL: https://www.fitbit.com/us/technology [accessed 2020-02-04]

68. Ethica Data Inc. 2020. Product. Ethica URL: https://ethicadata.com/product [accessed 2020-02-04]

69. REDCap. Software. Nashville: Vanderbilt University; 2020. URL: https://projectredcap.org/software/ [accessed 2020-02-05]

\title{
Abbreviations \\ MMS: multimedia messaging service \\ PHT: persuasive health technology \\ SMS: short message service \\ WHO: World Health Organization
}

\author{
Edited by T Risling; submitted 12.04.20; peer-reviewed by L Brosseau, H Akram; comments to author 24.05.20; revised version \\ received 26.05.20; accepted 10.06.20; published 15.07.20 \\ Please cite as: \\ McLean A \\ mHealth Apps as Effective Persuasive Health Technology: Contextualizing the "Necessary" Functionalities \\ JMIR Nursing 2020;3(1):e19302 \\ URL: https://nursing.jmir.org/2020/1/e19302/ \\ doi: $\underline{10.2196 / 19302}$ \\ PMID: 34345788
}

(C)Allen McLean. Originally published in JMIR Nursing Informatics (https://nursing.jmir.org), 15.07.2020. This is an open-access article distributed under the terms of the Creative Commons Attribution License (https://creativecommons.org/licenses/by/4.0/), which permits unrestricted use, distribution, and reproduction in any medium, provided the original work, first published in the Journal of Medical Internet Research, is properly cited. The complete bibliographic information, a link to the original publication on http://www.jmir.org/, as well as this copyright and license information must be included. 